\title{
Minimum sample frequency for multichannel intraluminal impedance measurement of the oesophagus
}

\author{
A. J. BREDENOORD, ${ }^{\star}$ B. L. A. M. WEUSTEN,${ }^{\star}$ R. TIMMER ${ }^{\star} \&$ A. J. P. M. SMOUT $\dagger$ \\ *Department of Gastroenterology, Saint Antonius Hospital, Nieuwegein, The Netherlands \\ $\dagger$ Gastrointestinal Research Unit, University Medical Center, Utrecht, The Netherlands
}

\begin{abstract}
In all systems for impedance monitoring signals are stored in digital format after analogto-digital conversion at a predefined rate, the sample frequency. We aimed to find the minimum sample frequency required to evaluate oesophageal transit and gastro-oesophageal reflux studies using impedance monitoring. In 10 healthy subjects and five patients with gastro-oesophageal reflux disease impedance signals were acquired during a 90-min postprandial period, using a sample frequency of $1000 \mathrm{~Hz}$. Additionally, 10 liquid swallows were recorded in the healthy subjects. A dedicated computer program was used to derive, from the original $1000-\mathrm{Hz}$ files, series of new data files with sample frequencies of 500, 200, 100,50,20,10, 8, 5 and $4 \mathrm{~Hz}$. In all of these files, liquid and gas reflux events were identified. In the analysis of the swallows, bolus head advance time (BHAT) and total bolus transit time were measured. Reflux events were detectable down to a sample frequency of $50 \mathrm{~Hz}$. In transit analysis errors for BHAT at frequencies below $8 \mathrm{~Hz}$ errors exceeded $2.5 \%$. Therefore, in impedance monitoring the minimum sample frequency is $50 \mathrm{~Hz}$ for the detection of reflux and $8 \mathrm{~Hz}$ for the evaluation of oesophageal transit.
\end{abstract}

Keywords electrical impedance, gastro-oesophageal reflux, oesophageal motility, oesophageal transit testing.

\section{INTRODUCTION}

Recently, intraluminal electrical impedance monitoring was introduced as a novel method to study bolus transport in oral and aboral direction in luminal organs. ${ }^{1,2}$ Impedance measurement provides information about bolus transport during oesophageal peristalsis and has already been incorporated in routine function testing in some tertiary medical centres., ${ }^{3,4}$ Studies combining impedance measurements with $\mathrm{pH}$-metry provide new insights into pathophysiology of gastrooesophageal reflux disease (GORD) and oesophageal acid clearance. ${ }^{5-7}$ Furthermore, intraluminal impedance can be used to study aerophagia and belching. ${ }^{8}$ Impedance measurements are also promising in the evaluation of reflux and regurgitation in paediatric practice. ${ }^{9,10}$

In all systems for intraluminal impedance monitoring the signals are stored in digital format after analogto-digital (A/D) conversion. A/D conversion is done at a predefined rate, the sample frequency.

In order to be able to recognize events like bolus transit, liquid reflux, gas reflux and belches in intraluminal impedance signals a sufficiently high sample frequency is necessary. The disadvantage of a high sample frequency is that the size of the data files becomes huge, especially when measuring for $24 \mathrm{~h}$. In previous studies using oesophageal impedance monitoring sample frequencies ranging from 30 to $1000 \mathrm{~Hz}$ were used, as no systematic study has been done to investigate the minimum sample frequency. ${ }^{8,11,12}$ In this study, we aimed to find the minimum sample frequency required to evaluate oesophageal transit, gastro-oesophageal reflux and belching using oesophageal impedance monitoring.

\section{METHODS}

A. J. Bredenoord MD, Department of Gastroenterology, Saint Antonius Hospital, P.O. Box 2500,

3430 EM Nieuwegein, The Netherlands.

Tel: +31 30 6093246; fax: +31 30 6056357;

e-mail: a.bredenoord@antonius.net

Received: 17 March 2004

Accepted for publication: 6 May 2004

\section{Subjects}

We recorded oesophageal intraluminal impedance in 10 healthy volunteers (four males and six females; mean 
age: 24 years; range: 22-33 years), five patients with GORD (four males and one female; mean age: 35 years; range: 26-53 years) and five patients with frequent belching (two males and three females; mean age: 48 ; range: $28-58$ years). The GORD patients had symptoms of heartburn and regurgitation as well as a pathological 24-h $\mathrm{pH}$-metric study (time with $\mathrm{pH}<4$ of more than $4.2 \%$ of total time). The patients with excessive belching fulfilled Rome II criteria for aerophagia and had a history of repetitive, troublesome belching without any organic disorder of the oesophagus or stomach. ${ }^{13}$ Healthy subjects were free of any gastrointestinal symptoms and were not taking any medication. Written informed consent was obtained from all subjects and the protocol was approved by the Medical Ethics Committee of the University Medical Center, Utrecht.

\section{Study protocol}

A routine oesophageal manometry was performed to determine the distance from nostrils to lower oesophageal sphincter (LOS). Thereafter the impedance catheter was introduced transnasally and positioned with its distal electrode at the upper border of the LOS. After an adaptation period of at least 10 min recording was started. Subjects remained seated during the course of the study and were asked to minimize head movements. In the healthy subjects, 10 swallows of $5 \mathrm{~mL}$ water each were given $30 \mathrm{~s}$ apart. A standardized meal was offered to all subjects consisting of one hamburger (McDonald's Quarter Pounder), $20 \mathrm{~g}$ of fresh onions, $44 \mathrm{~g}$ of potato chips and $475 \mathrm{~mL}$ of orange juice (in total $967 \mathrm{kCal}$ ). This meal was used to elicit reflux in a previous study by our group. ${ }^{14}$ Recordings were continued until 90 min after the meal.

\section{Intraluminal electrical impedance assembly}

A 7-channel impedance system was used (Aachen University of Technology, FEMU, Aachen, Germany). ${ }^{2,3}$ The catheter (diameter $2.3 \mathrm{~mm}$ ) contained 11 ring electrodes. From these 11 electrodes, seven impedance signals were recorded. The recording segments were located at 0-2, 2-4, 4-6, 8-10, 10-12, 14-16 and 17-19 above the upper border of the manometrically located LOS (Fig. 1). Impedance signals were sampled at $1000 \mathrm{~Hz}$.

\section{Data analysis}

Previously established criteria were used to analyze bolus transit events following the wet swallows in the healthy subjects before the meal and to identify gas

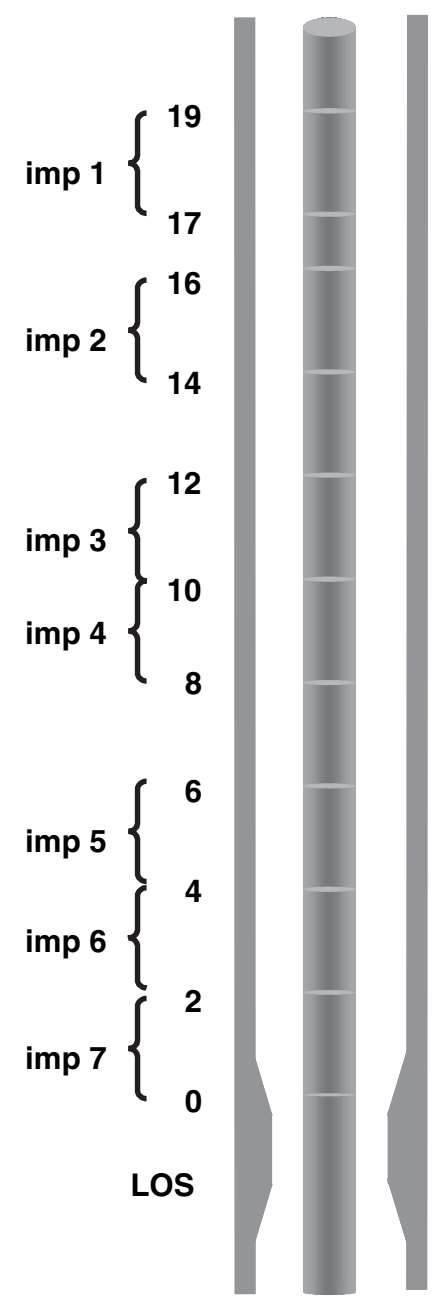

Figure 1 Position of the impedance catheter in the esophagus with respect to the manometric upper border of the lower oesophageal sphincter.

reflux and liquid reflux during the postprandial recording period in the healthy volunteers and the GORD patients. ${ }^{12,15,16}$ Regular gastric belches were identified as gas reflux from the stomach to the oesophagus and up to the pharynx. We furthermore identified 10 'supragastric belches' in each of the patients with excessive belching. In contrast to regular belches (gas reflux), these supragastric belches are immediately preceded by a rapid antegrade flow of air in the oesophagus that does not reach the stomach. ${ }^{8}$ Supragastric belches were found to be the predominant mechanism of excessive belching in patients with aerophagia. $^{8}$

A specially designed computer program was used to derive, from each of the digital $1000-\mathrm{Hz}$ impedance data files, new data files with sample frequencies of 500, 200, 100, 50, 20, 10, 8, 5 and $4 \mathrm{~Hz}$. This was 
accomplished by copying every first sample out of every $n$ samples of the $1000-\mathrm{Hz}$ file to the new file ( $n=1000 /$ new sample frequency).

In the analysis of the readings of the wet swallows, bolus head advance time (BHAT) along the catheter and total bolus transit time (TBTT) along the catheter were measured for all frequencies. Definitions for these parameters were adopted from Tutuian et al. (4) (Fig. 2). Time of bolus entry was defined as the point at which impedance had fallen to a value below $50 \%$ of the 3-s baseline level before initiation of the swallow. Bolus exit was determined as return to this $50 \%$ point on the impedance recovery curve.

The amplitudes of the swallow-associated impedance events at channel 5 (5 cm above the LES) were measured as the difference in impedance value between baseline and nadir impedance. This was performed for all of the different frequencies.

In the analysis of the liquid and gas reflux episodes, the amplitude of the impedance events /difference between baseline and lowest value for liquid, difference between baseline and highest value for gas) was measured in impedance channel 5 (5 cm above the LES) (Fig. 2). For each impedance event it was determined whether the propagation direction observed in the $1000-\mathrm{Hz}$ signals could also be observed in the reduced frequency signals. Furthermore, for reflux events and belches the propagating velocity of these events was calculated for all frequencies. This was done by dividing the distance along the catheter over which the liquid (liquid reflux) or gas (gas reflux and belches) bolus front travelled by the time.

Errors in the measurement of propagating velocity, BHAT and TBTT were calculated by comparing values at all the different sample frequencies with the value for these parameters calculated at $1000 \mathrm{~Hz}$. The cut-off level for maximal acceptable error in BHAT and TBTT was arbitrarily set to $2.5 \%$.

\section{Statistical analysis and presentation of data}

Throughout the manuscript data are presented as mean \pm SEM. The Student's $t$-test was used to assess differences between GORD patients and healthy volunteers. Differences were considered to be statistically significant when $P \leq 0.05$.

\section{RESULTS}

In the healthy volunteers 33 liquid reflux and 30 gas reflux episodes were identified. Mean propagation velocities of liquid and gas reflux, when measured at $1000 \mathrm{~Hz}$, were $0.71 \pm 0.07$ and $1.15 \pm 0.14 \mathrm{~m} \mathrm{~s}^{-1}$,
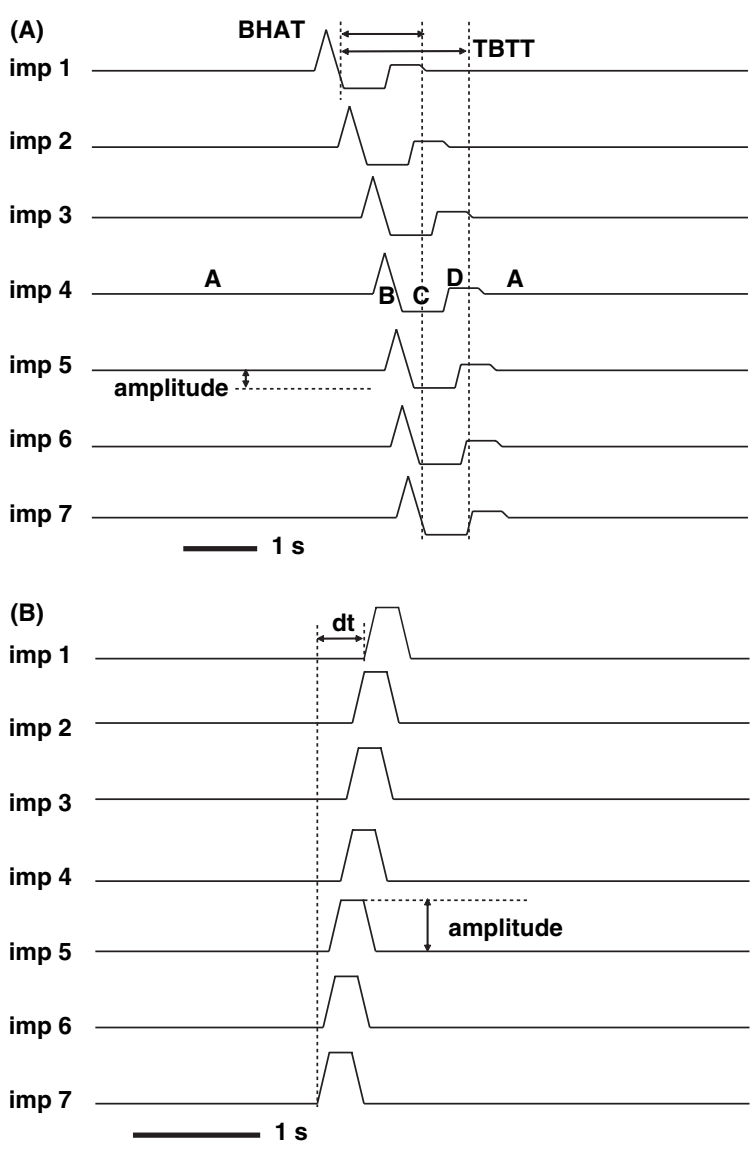

Figure 2 A: Determination of total bolus transit time (TBTT) and bolus head advance time (BHAT). TBTT is defined as the elapsed time from bolus entry in the most proximal segment to bolus clearance in the most distal segment. BHAT is defined as the elapsed time from bolus entry in the most proximal segment to bolus entry in the most distal segment. (A) Baseline impedance. (B) Gas, pushed in front of the bolus and recognized by an increase in impedance. (C) Decrease in impedance representing liquid bolus. (D) Increase in impedance after the bolus, representing a contraction wave. B: Determination of gas reflux propagation velocity. Gas reflux is characterized by an increase in impedance that moves in oral direction. The dotted lines represent the onset of the increase in impedance in the most distal and most proximal measuring segment, indicating gas entry. Propagation velocity is calculated as $V=\mathrm{d} x / \mathrm{d} t$ with $\mathrm{d} x$ as the distance between impedance segment 7 and the most proximal measuring segment reached by the reflux.

respectively. In the GORD patients 17 liquid reflux and 12 gas reflux episodes were observed. Mean propagation velocities of liquid and gas reflux, when measured at $1000 \mathrm{~Hz}$, were $0.58 \pm 0.16$ and $1.02 \pm$ $0.31 \mathrm{~m} \mathrm{~s}^{-1}$, respectively. As these were not significantly different from values in the healthy volunteers, we pooled data from these two groups for the determination of minimum sample frequency. The 
percentage of gas and liquid reflux that extended to the most proximal impedance segment was 76.0 and $23.8 \%$, respectively. As shown in Table 1, the detection of propagation of gaseous and liquid reflux events remained possible down to a sample frequency of $50 \mathrm{~Hz}$. At lower frequencies reflux could not always be recognized as moving in oral direction because the impedance change in the most distal and the most proximal impedance channel reached by the reflux started at the same data sample (Fig. 3). The increasing loss in detail in gas and liquid reflux events that occurs at lower sample frequencies is illustrated in Fig. 4. Table 1 also shows the difference between the amplitude of reflux events at $1000 \mathrm{~Hz}$ and at the other frequencies. Whereas the errors in amplitude measurement remained small for liquid reflux events, the errors for gas reflux events exceeded $10 \%$ when frequencies were reduced below $50 \mathrm{~Hz}$. Error in amplitudes did not impair detection of reflux events.

The impact of reduction of sample frequency was most pronounced for the supragastric belches (Table 1). None of these belches could be recognized at $4 \mathrm{~Hz}$. The mean propagation velocity of the supragastric belches was $2.33 \pm 0.13 \mathrm{~m} \mathrm{~s}^{-1}$, i.e. even faster than that of gas reflux.

At a sample frequency of $1000 \mathrm{~Hz}$ the transit parameters BHAT and TBTT were $2.47 \pm 0.13$ and $7.09 \pm 0.32 \mathrm{~s}$, respectively. As shown in Table 2 , the errors made in the measurements of these parameters remained less than $2.5 \%$ when sample frequencies were reduced as far as to $8 \mathrm{~Hz}$. Likewise, the error made in measurement of the amplitude of liquid

Table 1 Failure to determine propagation direction $(\%)$ and error $(\%)$ in measurement of propagation velocity and amplitude of liquid and gas reflux events and supragastric belches at different sample frequencies, as compared to $1000 \mathrm{~Hz}$

\begin{tabular}{|c|c|c|c|c|c|c|c|c|c|}
\hline \multirow[b]{2}{*}{$\begin{array}{l}\text { Sample } \\
\text { frequency }\end{array}$} & \multicolumn{3}{|l|}{ Liquid reflux } & \multicolumn{3}{|c|}{ Gaseous reflux } & \multicolumn{3}{|c|}{ Supragastric belch } \\
\hline & $\begin{array}{l}\text { Propagation } \\
\text { undetectable } \\
(\%)\end{array}$ & $\begin{array}{l}\text { Error } \\
\text { velocity } \\
(\%)\end{array}$ & $\begin{array}{l}\text { Error } \\
\text { amplitude } \\
(\%)\end{array}$ & $\begin{array}{l}\text { Propagation } \\
\text { undetectable } \\
(\%)\end{array}$ & $\begin{array}{l}\text { Error } \\
\text { velocity } \\
(\%)\end{array}$ & $\begin{array}{l}\text { Error } \\
\text { amplitude } \\
(\%)\end{array}$ & $\begin{array}{l}\text { Propagation } \\
\text { undetectable } \\
(\%)\end{array}$ & $\begin{array}{l}\text { Error } \\
\text { velocity } \\
(\%)\end{array}$ & $\begin{array}{l}\text { Error } \\
\text { amplitude } \\
(\%)\end{array}$ \\
\hline 500 & 0.0 & 0.5 & 0.0 & 0.0 & 1.2 & 0.1 & 0.0 & 3.4 & 0.0 \\
\hline 200 & 0.0 & 5.2 & 0.0 & 0.0 & 4.3 & 0.3 & 0.0 & 11.3 & 0.1 \\
\hline 100 & 0.0 & 8.3 & 0.0 & 0.0 & 11.9 & 0.4 & 0.0 & 14.2 & 0.0 \\
\hline 50 & 0.0 & 10.5 & 0.0 & 0.0 & 19.6 & 2.2 & 0.0 & 17.4 & 0.4 \\
\hline 20 & 0.0 & 30.5 & 0.1 & 9.5 & 32.3 & 12.6 & 18.0 & 40.9 & 1.9 \\
\hline 10 & 0.0 & 24.9 & 0.1 & 35.7 & 34.5 & 24.9 & 48.0 & 42.4 & 14.2 \\
\hline 8 & 0.0 & 47.2 & 0.5 & 38.1 & 39.3 & 24.1 & 54.0 & 45.7 & 14.3 \\
\hline 5 & 2.0 & 32.1 & 14.9 & 59.5 & 53.1 & 25.3 & 80.0 & 59.8 & 19.8 \\
\hline 4 & 5.0 & 47.3 & 13.8 & 61.9 & 79.0 & 27.0 & 100.0 & - & 17.2 \\
\hline
\end{tabular}

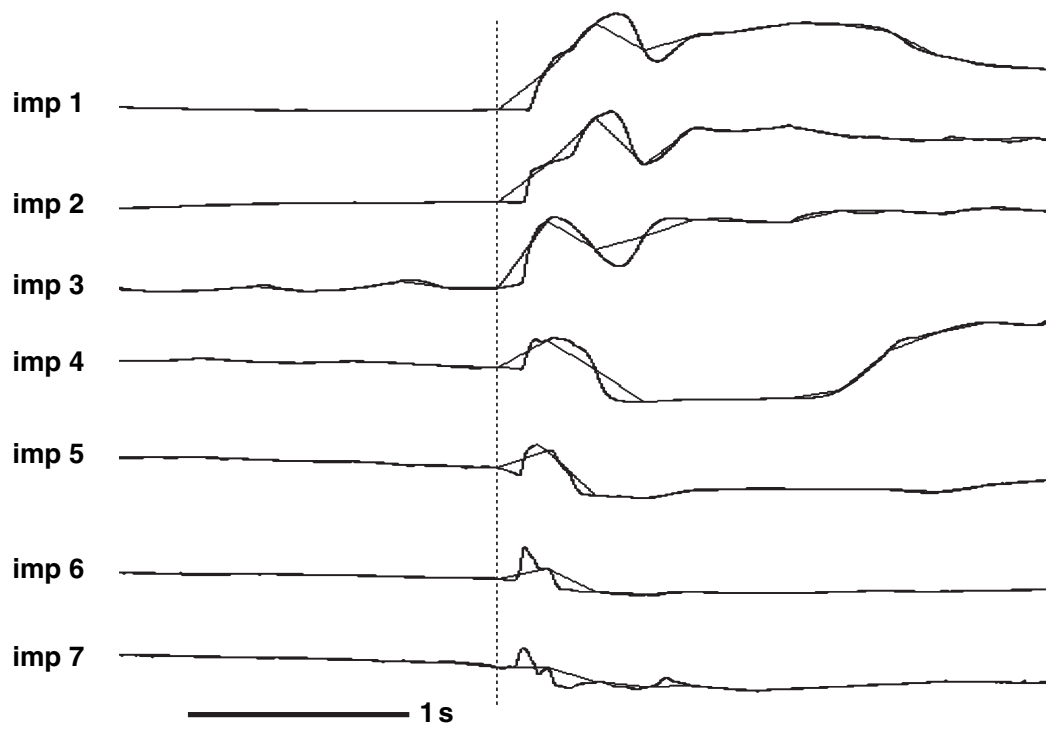

Figure 3 Example of a gas reflux episode, recognizable by an increase in impedance that propagates in oral direction, displayed at 1000 and at $5 \mathrm{~Hz}$. At $1000 \mathrm{~Hz}$ the gas reflux event is clearly propagating from distal to proximal. In the $5-\mathrm{Hz}$ tracing, the increase in impedance is simultaneous in all channels (dotted line). This makes it impossible to determine the direction of the movement of the gas bolus. 
Figure 4 (A) Example of a gas reflux episode at different sample frequencies. With the reduction of the sample frequency, an increasing loss is seen in detail. At $8 \mathrm{~Hz}$ the direction is still recognizable, at $5 \mathrm{~Hz}$ the impedance rise of the reflux event at the proximal and distal channel appears simultaneous, making the direction of the propagation indeterminable. (B) Example of a liquid reflux episode at different sample frequencies. While an increasing loss in detail is obtained with reduction of sample frequency, the oral propagation direction is recognizable at all sample frequencies.

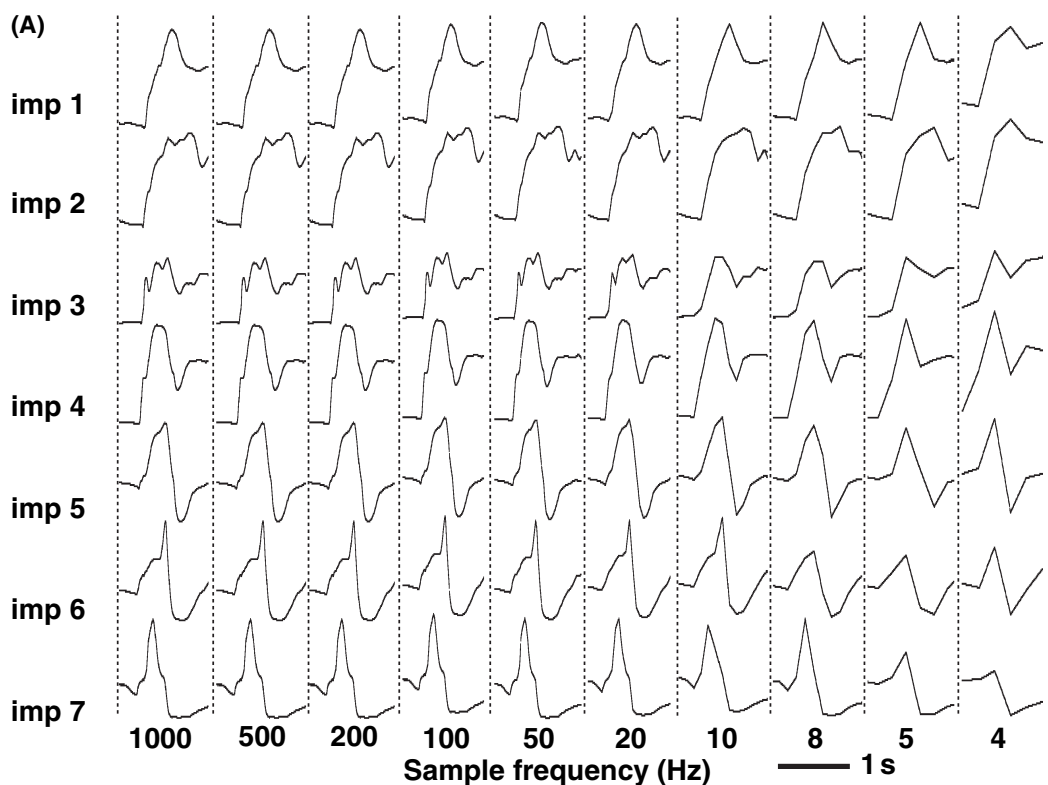

(B)

imp 1

imp 2

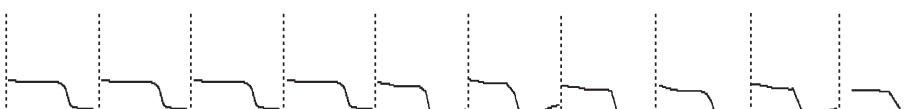

mp 3

imp 4

$\operatorname{imp} 5$

imp 6

imp 7

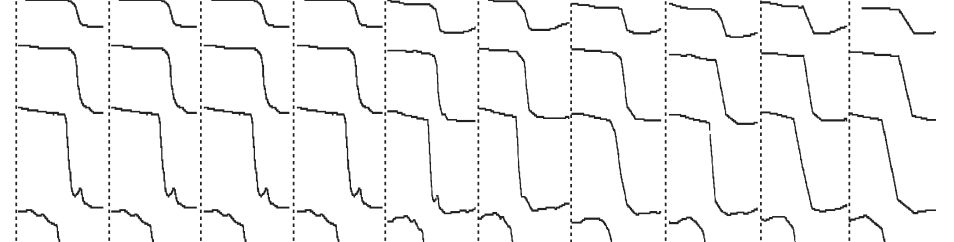

transit-associated impedance drops was small (4.9\% at $4 \mathrm{~Hz}$ ). As a result, all swallows could be clearly recognized, even when the sample frequency was reduced to $4 \mathrm{~Hz}$ (Fig. 5).

\section{DISCUSSION}

This is the first paper addressing the minimally required sample frequency for intraluminal electrical impedance measurement of the oesophagus. Using specially designed software we were able to show that a reduction in sample frequency results in an increasing loss in detail of impedance tracings. The error at lower sample frequencies is larger for events with a high propagation velocity, such as gas reflux and supragastric belches. While at $20 \mathrm{~Hz}$ propagation direction is undeterminable in as many as $9.5 \%$ of gas reflux events, all of the slower propagating liquid reflux events are still recognizable. The magnitude of the error at the lower sample frequencies is much larger for reflux events and for supragastric belches than for the bolus transit parameters TBTT and BHAT. This implies that it is justifiable to use a lower sample frequency for oesophageal transit tests than for reflux testing. If an appropriate sample frequency is defined as one at which the direction of propagation of the 
Table 2 Error in measurement of total bolus transit time (TBTT), bolus head advance time (BHAT) and amplitude of the liquid bolus at different sample frequencies as compared to values at $1000 \mathrm{~Hz}$

\begin{tabular}{clcl}
\hline & TBTT error $(\%)$ & BHAT error $(\%)$ & Amplitude error $(\%)$ \\
\hline 500 & 0.1 & 0.1 & 0.0 \\
200 & 0.4 & 0.8 & 0.0 \\
100 & 0.4 & 1.9 & 0.0 \\
50 & 0.7 & 1.1 & 0.2 \\
20 & 0.8 & 2.0 & 0.1 \\
10 & 1.1 & 1.6 & 2.2 \\
8 & 2.3 & 1.9 & 2.0 \\
5 & 2.1 & 3.3 & 2.4 \\
4 & 2.7 & 10.7 & 4.9 \\
\hline
\end{tabular}

refluxate is distinguishable in $100 \%$ of the cases, a sample frequency of at least $50 \mathrm{~Hz}$ is required for monitoring of gastro-oesophageal reflux. This finding justifies a considerable reduction in data file size compared to the currently used sample frequencies. Recording for $24 \mathrm{~h}$ of seven impedance signals with a sample frequency of $1000 \mathrm{~Hz}$, requires a storage capacity in the order of 900 megabyte. A 20 -fold reduction of sample frequency, from 1000 to $50 \mathrm{~Hz}$, will be associated with a similar reduction in data file size (to $45 \mathrm{Mb}$ ) and processing time. As the errors in amplitude of the impedancometric events are smaller at the given frequencies than the errors in propagation velocity, we do not consider this parameter to be a limiting factor. It might be useful to use a higher sample frequency for specific research purposes. When one uses a sample frequency of $50 \mathrm{~Hz}$ for gas reflux studies, all events are recognized, but an error in the measured propagation velocity of almost $20 \%$ is found. Increasing the sample frequency will result in a more precise estimation of this parameter. We also tested minimum sample frequency for detection of supragastric belches as these events propagate even more rapid than gas reflux and would therefore possibly require a higher sample frequency. ${ }^{8}$ It was found that aerophagia and supragastric belches can be studied at $50 \mathrm{~Hz}$ as all events are recognized but, given the large error in propagation velocity, a higher sample frequency might be useful in scientific studies.

Mixed reflux is defined as the simultaneous occurrence of both liquid and gas reflux. To recognize this correctly, both components have to be identified. Therefore, we did not feel the need to distinguish mixed reflux as a separate category. As gas reflux propagates much faster, recognition of mixed reflux events at lower sample frequencies depends on identification of the gas reflux component.

A sample frequency of $50 \mathrm{~Hz}$ for impedance monitoring contrasts to the sample frequency of 1 or $2 \mathrm{~Hz}$ that is mostly used for $\mathrm{pH}$-metric studies. The low response rate of both glass and antimony $\mathrm{pH}$ electrodes makes that higher sample frequencies are not contributory. Furthermore, in most studies with $\mathrm{pH}$ monitoring, one sensor is used and reflux is recognized when $\mathrm{pH}$ falls below 4. For recognition of reflux with intraluminal electrical impedance both information about the change in impedance in several adjacent channels and information about the sequence of the

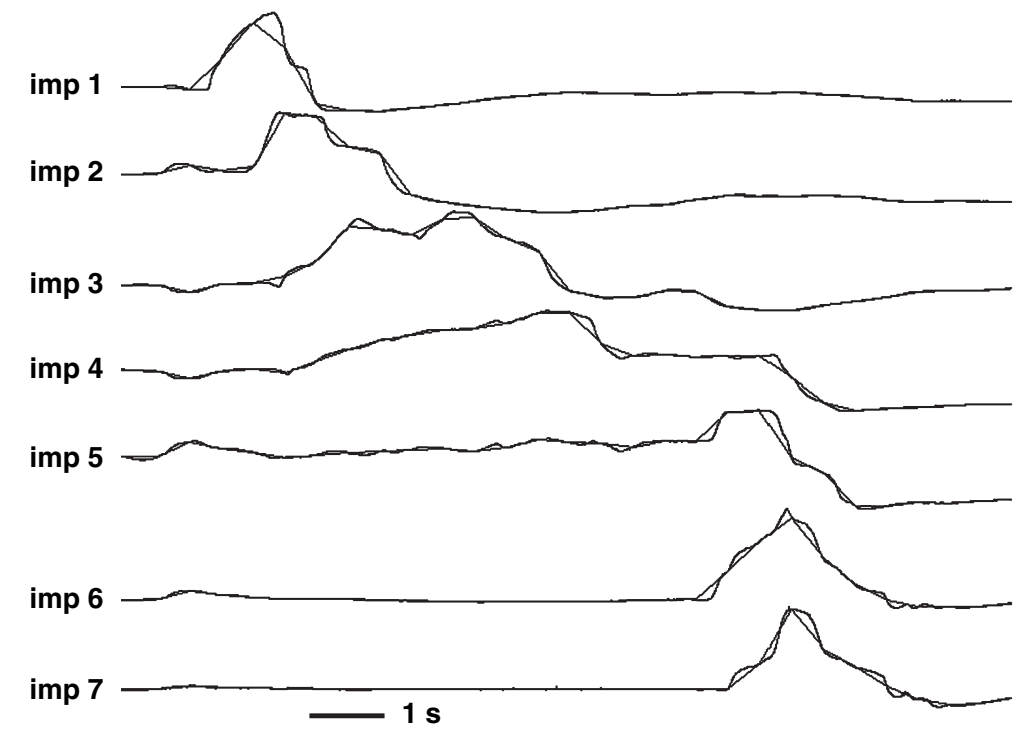

718
Figure 5 Example of peristalsis after a liquid swallow, displayed at 1000 and $5 \mathrm{~Hz}$. In a relatively slow event as a swallow, differences between recordings at $1000 \mathrm{~Hz}$ and $5 \mathrm{~Hz}$ are small. 
channels in which this change occurs are required. For this, a higher time resolution is needed compared to $\mathrm{pH}$ monitoring.

The mean values of the parameters BHAT and TBTT, used for testing of swallowing and oesophageal peristalsis, are $2.47 \pm 0.13$ and $7.09 \pm 0.32 \mathrm{~s}$, respectively, well within the normal range of liquid bolus transport given by a multicenter report. ${ }^{4}$ These events are relatively slow, compared to liquid and gas reflux events and supragastric belches, and errors from values at $1000 \mathrm{~Hz}$ at lower frequencies are much smaller. Even at $8 \mathrm{~Hz}$, a relatively accurate estimation of BHAT, TBTT and the amplitude of impedance change can be made. Our recommendation of the use of a sample frequency of $8 \mathrm{~Hz}$ is less strict than the use of $50 \mathrm{~Hz}$ for reflux monitoring, as swallow parameters are still recognizable and interpretable at lower frequencies than $8 \mathrm{~Hz}$.

Determination of the optimal sample frequency in this study was based on a seven-segment catheter with $17 \mathrm{~cm}$ between the most proximal and most distal measuring segment. A substantial part of reflux does not reach the most proximal impedance segment. Such events are harder to recognize with a low sample frequency as propagation distance is shorter and, therefore, the likelihood that they occur in the same sample is higher. The aim of this study was to find the sample frequency at which all reflux events could be detected and therefore we used all reflux episodes for analysis. This makes that our conclusions are valid for both limited gastro-oesophageal reflux as for reflux that extends to the proximal oesophagus.

In conclusion, using stepwise reduction of the sample frequency from 1000 to $4 \mathrm{~Hz}$ we determined the minimum sample frequencies required for oesophageal impedance measurements. The results indicate that the minimum frequency is $50 \mathrm{~Hz}$ for reflux monitoring and $8 \mathrm{~Hz}$ for oesophageal transit testing.

\section{ACKNOWLEDGMENTS}

A.J. Bredenoord was supported by a clinical research trainee grant from Janssen-Cilag, The Netherlands.

\section{REFERENCES}

1 Silny J. Intraluminal multiple electric impedance procedure for measurement of gastrointestinal motility. $I$ Gastrointest Mot 1991; 3: 151-62.

2 Silny J, Knigge KP, Fass J, Rau G, Matern S, Schumpelick V. Verification of the intraluminal multiple electrical impedance measurement for the recording of gastrointestinal motility. J Gastrointest Mot 1993; 5: 107-22.

3 Fass J, Silny J, Braun J et al. Measuring esophageal motility with a new intraluminal impedance device. First clinical results in reflux patients. Scand J Gastroenterol 1994; 29: 693-702.

4 Tutuian R, Vela M, Nagammapudur S et al. Esophageal function testing with combined multichannel intraluminal impedance and manometry: multicenter study in healthy volunteers. Clin Gastroenterol Hepatol 2003; 1: 174-82.

5 Sifrim D, Holloway R, Silny J, Tack J, Lerut A, Janssens J. Composition of the postprandial refluxate in patients with gastroesophageal reflux disease. Am J Gastroenterol 2001; 96: $647-55$.

6 Simren M, Silny J, Holloway R, Tack J, Janssens J, Sifrim D. Relevance of ineffective oesophageal motility during oesophageal acid clearance. Gut 2003; 52: 784-90.

7 Vela MF, Camacho-Lobato L, Srinivasan R, Tutuian R, Katz PO, Castell DO. Simultaneous intraesophageal impedance and $\mathrm{pH}$ measurement of acid and nonacid gastroesophageal reflux: effect of omeprazole. Gastroenterology 2001; 120: 1599-606.

8 Bredenoord AJ, Weusten BL, Sifrim D, Timmer R, Smout AJ. Aerophagia, gastric and supragastric belching. A study using intraluminal electrical impedance monitoring. Gut 2004; 53.

9 Wenzl TG, Schneider S, Scheele F, Silny J, Heimann G, Skopnik H. Effects of thickened feeding on gastroesophageal reflux in infants: a placebo-controlled crossover study using intraluminal impedance. Pediatrics 2003; 111: e355-9.

10 Wenzl TG, Moroder C, Trachterna M et al. Esophageal pH monitoring and impedance measurement: a comparison of two diagnostic tests for gastroesophageal reflux. I Pediatr Gastroenterol Nutr 2002; 34: 519-23.

11 Peter CS, Wiechers C, Bohnhorst B, Silny J, Poets CF. Detection of small bolus volumes using multiple intraluminal impedance in preterm infants. I Pediatr Gastroenterol Nutr 2003; 36: 381-4.

12 Sifrim D, Silny J, Holloway RH, Janssens JJ. Patterns of gas and liquid reflux during transient lower oesophageal sphincter relaxation: a study using intraluminal electrical impedance. Gut 1999; 44: 47-54.

13 Talley NJ, Stanghellini V, Heading RC, Koch KL, Malagelada JR, Tytgat GN. Functional gastroduodenal disorders. Gut 1999; 45: II37-42.

14 Van Herwaarden MA, Samsom M, Rydholm H, Smout AJ. The effect of baclofen on gastro-oesophageal reflux, lower oesophageal sphincter function and reflux symptoms in patients with reflux disease. Aliment Pharmacol Ther 2002; 16: 1655-62.

15 Tutuian R, Elton JP, Castell DO, Gideon RM, Castell JA, Katz PO. Effects of position on oesophageal function: studies using combined manometry and multichannel intraluminal impedance. Neurogastroenterol Motil 2003; 15: 63-7.

16 Skopnik H, Silny J, Heiber O, Schulz J, Rau G, Heimann G. Gastroesophageal reflux in infants: evaluation of a new intraluminal impedance technique. I Pediatr Gastroenterol Nutr 1996; 23: 591-8. 